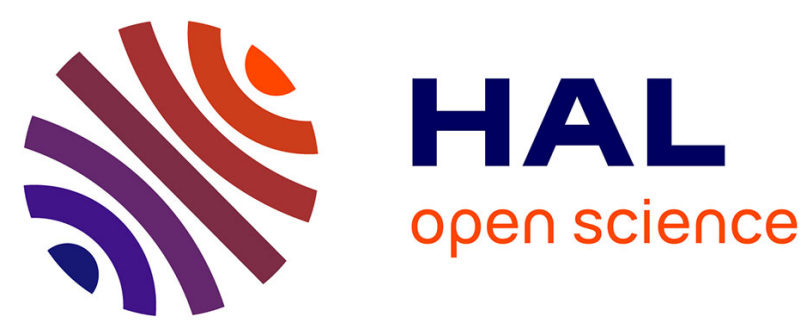

\title{
Bioprospecting of strains of Streptococcus thermophilus from Indian fermented milk products for folate production
}

Ramya Iyer, Sudhir Kumar Tomar, Ashok Kumar Mohanty, Prashant Singh, Rameshwar Singh

\section{To cite this version:}

Ramya Iyer, Sudhir Kumar Tomar, Ashok Kumar Mohanty, Prashant Singh, Rameshwar Singh. Bioprospecting of strains of Streptococcus thermophilus from Indian fermented milk products for folate production. Dairy Science \& Technology, 2011, 91 (2), pp.237-246. 10.1007/s13594-011-0011-z . hal-00874811

\section{HAL Id: hal-00874811 \\ https://hal.science/hal-00874811}

Submitted on 18 Oct 2013

HAL is a multi-disciplinary open access archive for the deposit and dissemination of scientific research documents, whether they are published or not. The documents may come from teaching and research institutions in France or abroad, or from public or private research centers.
L'archive ouverte pluridisciplinaire HAL, est destinée au dépôt et à la diffusion de documents scientifiques de niveau recherche, publiés ou non, émanant des établissements d'enseignement et de recherche français ou étrangers, des laboratoires publics ou privés. 


\title{
Bioprospecting of strains of Streptococcus thermophilus from Indian fermented milk products for folate production
}

\author{
Ramya Iyer • Sudhir Kumar Tomar • \\ Ashok Kumar Mohanty • Prashant Singh • \\ Rameshwar Singh
}

Received: 14 April 2010 /Revised: 1 July 2010 / Accepted: 15 July 2010 /

Published online: 23 March 2011

(C) INRA and Springer Science+Business Media B.V. 2011

\begin{abstract}
This study deals with the bio-prospecting of folate producing strains of Streptococcus thermophilus isolated from milk and different fermented milk products of Indian origin. From a total of 500 randomly selected colonies isolated from 209 different samples, 117 isolates were identified as S. thermophilus by classical biochemical and molecular characterization. Frequency of incidence of $S$. thermophilus in the different samples of milk and milk products was variable with the highest in the dahi followed by yogurt and lassi and a very low incidence in case of milk and cheese. On screening for folate using a microbiological assay with a trienzyme extraction, about $15 \%$ of strains was found to produce folate in the range of $40-50 \mu \mathrm{g} \cdot \mathrm{L}^{-1}, 35 \%$ in the range of $20-30 \mu \mathrm{g} \cdot \mathrm{L}^{-1}$, and the remainder in the range of 4-16 $\mu \mathrm{g} \cdot \mathrm{L}^{-1}$. Comparative analysis of the random amplification of polymorphic DNA PCR fingerprint profiles was used to characterize interspecific diversity of the ten highest folate producers. The LacZ gene of two of the highest folate producing isolates were sequenced and submitted to GenBank under following accession numbers of FJ161697 and FJ161698.
\end{abstract}

R. Iyer $\cdot$ S. K. Tomar $(\bowtie) \cdot$ P. Singh $\cdot$ R. Singh

Dairy Microbiology Division, National Dairy Research Institute, Karnal 132 001, India e-mail: sudhirndri@gmail.com

R. Iyer

e-mail: ramyaiyer.micro@gmail.com

P. Singh

e-mail: prashantforu@gmail.com

R. Singh

e-mail: rsndri@gmail.com

\section{A. K. Mohanty}

Animal Biotechnology Division, National Dairy Research Institute, Karnal 132001, India

e-mail: ashokmohanty@gmail.com 


\section{印度发酵乳制品中产叶酸嗜热链球菌株的生物勘探}

摘要 本文利用生物勘探方法研究了印度牛乳及发酵乳制品中产叶酸的嗜热链球 菌株。从 209 个样本中随机选取了 500 个菌落, 通过经典的生物化学和分子生 物学方法确定 117 株为嗜热链球菌。在 Dali 样品中, 嗜热链球菌含量较高, 其 次是酸乳和 lassi, 由此可见, 在这些牛乳和发酵乳制品中的菌株生物多样性为 嗜热链球菌占主要部分。采用三重酶提取微生物学测定法笁选产叶酸菌株, 发 现约 15\% 的菌株产叶酸的范围为 $40-50 \mu \mathrm{g} \cdot \mathrm{L}^{-1}, 35 \%$ 的菌株为 $20-30 \mu \mathrm{g} \cdot \mathrm{L}^{-1}$, 其余 的则在 4-16 $\mu \mathrm{g} \cdot \mathrm{L}^{-1}$ 之间。采用 RAPD - PCR 指纹图谱对比分析了 10 株产叶酸 最高菌株的种间多样性。对两株产叶酸含量最高菌株的 LacZ 基因进行测序, 将 序列提交到 GenBank 中得到序列号为 FJ161697 和 FJ161698。

Keywords Streptococcus thermophilus · Folate · Microbiological assay · Bioprospecting $\cdot$ Interspecific diversity

关键词 嗜热链球菌 (Streptococcus thermophilus) - 叶酸. 微生物学测定法. 生物勘探. 种间多样性

\section{Introduction}

Folates represent an essential nutritional component, which is involved in many metabolic pathways, mainly in carbon transfer reactions such as purine and pyrimidine biosynthesis and amino acid interconversions. The daily recommended intake of folate for an adult varies between 200 and $400 \mu \mathrm{g}$. A low folate intake has also been associated with a number of health disorders such as Alzheimer's and coronary heart diseases, osteoporosis, increased risk of breast and colorectal cancer, poor cognitive performance, hearing loss, neural tube defects, etc. (LeBlanc et al. 2007; Papastoyiannidis et al. 2006). Therefore, an exogenous supply of folic acid appears inevitable to prevent nutritional deficiency especially in view of the inability of mammalian cells to synthesize this vital biomolecule. However, a number of studies have shown that high intakes of folic acid, the chemically synthesized form of folate, but not natural folates can cause adverse affects in some individuals such as the masking of the hematological manifestations of vitamin B12 deficiency, leukemia, arthritis, bowel cancer, and ectopic pregnancies (LeBlanc et al. 2007; Wright et al. 2007). According to these latter studies, unlike natural folates, which are digested in the gut, synthetic folate supplements are metabolised in liver, and as the liver is an easily saturated system, mandatory fortification could lead to significant unmetabolised folic acid entering the blood. This could provoke a number of health complaints as reported above. Therefore, many researchers have been looking for novel methods to increase the concentration of naturally occurring folate variants in foods.

On average, milk and dairy products contribute $10-5 \%$ of the daily folate intake (Arcot et al. 2005; Forssen et al. 2000). As food grade bacteria tend to produce folate during fermentation, fermented milks contain the higher amounts of folate (Iyer et al. 2009; Lin and Young 2000). Numerous researchers have reported that lactic acid bacteria, such as Lactococcus lactis and Streptococcus thermophilus are endowed with the ability to synthesize folate (Crittenden et al. 2003; Tomar et al. 2009).

$S$. thermophilus is one of the most commercially important dairy starters after $L$. lactis, as it is used extensively for the manufacture of several important fermented 
dairy foods, including yogurt, Swiss cheese, Limburger cheese, Brick cheese, and other Italian variety cheeses (Delorme 2008; Hols et al. 2005; Tomar et al. 2009). The research on the physiology of $S$. thermophilus has yielded vital information both on its technological properties, such as lactose and galactose metabolism, and functional aspects, such as exopolysaccharide, bacteriocins, biosurfactants, and vitamins (Delorme 2008; Hols et al. 2005). Among these metabolites, $S$. thermophilus has a strain-specific ability to produce folate and has been reported to produce higher quantities of folate in comparison to other LAB, the majority of which is excreted into the milk (Crittenden et al. 2003; Holasova et al. 2004; Papastoyiannidis et al. 2006). Hence, the proper selection and use of folate producing microorganisms is an interesting strategy to increase "natural" folate levels in foods (LeBlanc et al. 2007; Tomar et al. 2009).

During the last four decades, numerous reports have been published (Forssen et al. 2000; LeBlanc et al. 2007) regarding the content of folate in food and the various methods of folate determination, including biological, microbiological, bio-specific procedures (radiobinding or immuno assay), chromatographic, electrochemical, or spectrophotometric methods, some of which are carried out in combination with gel or high-pressure liquid chromatography. Among these various methods of folate determination, the microbiological assay (MA) has been considered to be one of the best and most versatile (Iyer et al. 2009). The strain L. rhamnosus ATCC 7469 is the most accepted assay organism for folate analysis, which responds to natural folate forms present in food (Arcot et al. 2005).

Keeping in mind the natural biodiversity of strains of $S$. thermophilus with respect to folate production, the present study investigated the isolation and identification of strains of $S$. thermophilus from milk and Indian fermented milks and an estimation of their folate production by the modified microbiological assay.

\section{Materials and methods}

\subsection{Isolation from milk and milk products}

A total number of 209 commercial and domestic samples (samples of dahi traditionally made in Indian households) of milk and fermented milks, such as raw milk (23), dahi (50), and lassi, a buttermilk like indigenous drinking fermented milk product obtained by churning of dahi (26), yogurt (3), and cheese (8) from different regions, were procured for the study. These were serially diluted in phosphate buffered saline and plated on the selective M17 Agar (Himedia Laboratories Pvt. Ltd., Mumbai, India) and incubated at $42{ }^{\circ} \mathrm{C}$ for $48 \mathrm{~h}$. Subsequently, the colonies that showed typical Gram reaction and morphological characteristics were transferred to sterile skim milk tubes and were incubated at $42{ }^{\circ} \mathrm{C}$ for curdling and maintained in reconstituted skim milk (RSM, 10\% total solids) with subculturing after every 7 days. The culture National Collection of Dairy Cultures (NCDC) 177 was found to be the best folate producer $\left(32.14 \mu \mathrm{g} \cdot \mathrm{L}^{-1}\right)$ among the cultures of $S$. thermophilus available in the NCDC, National Dairy Research Institute (Karnal, Haryana 132001, India) in a previous work carried out in our laboratory and was taken as a positive control for this study (Tomar et al. 2009). 


\subsection{Biochemical characterization}

The curdled milk cultures were screened by microscopic examination and catalase test. These presumptive isolates were biochemically characterized by bile esculin hydrolysis, growth at 6.5\% NaCl, pH 9.5, 10 and $45{ }^{\circ} \mathrm{C}$. Sugar fermentation patterns were determined using $\mathrm{CHL}$ as a basal medium (fructose, glucose, mannose, dextrose, mannitol, rhamnose, salicin, sorbitol, and xylose) in anaerobic gas jar (GasPak ${ }^{\mathrm{TM}} 100$ System, BBL Systems, Cockeysville, MD, USA).

\subsection{Molecular identification}

The phenotypically characterized isolates were further genetically identified by species specific polymerase chain reaction (PCR) based on LacZ gene as previously described by Lick et al. (1996). S. thermophilus isolates were grown in M17 broth, and genomic DNA was extracted as previously described (Pospiech and Neumann 1995). PCR was performed for the identification of isolates on an Eppendorf Mastercycler (Hamburg, Germany) according to earlier published literature (Lick et al. 1996). Amplification was verified by electrophoresis on $1.5 \%(w / v)$ agarose gel in $1 \times$ Tris-acetate-EDTA buffer.

The lacZ gene sequence of the two highest folate producing $S$. thermophilus isolate RD 102 and RD 104 were PCR amplified, and the products were sequenced commercially by Chromous Biotech Pvt. Ltd. (Bangalore), and the gene sequence obtained was submitted to NCBI GenBank database.

\subsection{Screening for folate production}

All phenotypically and genotypically characterized $S$. thermophilus cultures were transferred from stock culture into $10 \mathrm{~mL}$ of sterile reconstituted skim milk (RSM$10 \% \mathrm{TS}$ ) and incubated at $42{ }^{\circ} \mathrm{C}$ for $24 \mathrm{~h}$. The folate concentrations of the samples were determined after incubation for $24 \mathrm{~h}$ by MA of folate with minor modifications as previously described (Tomar et al. 2009).

2.5 Characterization of genetic diversity of the high folate producing strains S. thermophilus strains

The ten best folate producing isolates (RL 3, RL 17, RD 49, RD 54, RL 72, RM 76, RD 95, RD 102, RD 104, and RD 108) were selected for characterization of genetic diversity. The interspecific differences of ten high folate producing isolates was characterized by random amplification of polymorphic DNA (RAPD)-PCR with two type strains $S$. thermophilus NCDC 177 and MTCC 1938 as standard cultures and comparative analysis of the PCR fingerprinting profiles similarity using two RAPD primers M13, 5'-GAGGGTGGCGGTTCT-3' (Botina et al. 2007) and AP4, 5'TCACGCTGCA-3' (Andrighetto et al. 2001).The RAPD-PCR was performed with minor modification in the annealing temperatures for both the primers. The PCR program was modified to $95{ }^{\circ} \mathrm{C}$ for $240 \mathrm{~s}\left(94{ }^{\circ} \mathrm{C}, 60 \mathrm{~s} ; 37.3^{\circ} \mathrm{C}, 45 \mathrm{~s}\right.$; and $72{ }^{\circ} \mathrm{C}$, $60 \mathrm{~s}), 40$ cycles; $72{ }^{\circ} \mathrm{C}, 4 \mathrm{~min}$ for M13 primer while for $\mathrm{AP} 4$ it was $94{ }^{\circ} \mathrm{C}, 120 \mathrm{~s}$ 
$\left(94{ }^{\circ} \mathrm{C}, 60 \mathrm{~s} ; 34.5^{\circ} \mathrm{C}, 60 \mathrm{~s}\right.$; and $72{ }^{\circ} \mathrm{C}, 60 \mathrm{~s}$ ), and 45 cycles, $72{ }^{\circ} \mathrm{C}, 4 \mathrm{~min}$. PCRamplified products obtained were electrophoresed on the agarose gels $(1.5 \%)$.

The images were normalized and analyzed using NTSYSpc 2.02 software package (Applied Biostatistics Inc., New York, USA). Grouping of the RAPD-PCR profiles was performed by calculating the similarity coefficients for pairs of tracks using Jaccard coefficient, and strains were grouped by sequential agglomerative hierarchal nested cluster analysis using the unweighted pair group method with arithmetic averages (UPGMA) clustering algorithm. The RAPD-PCR fingerprints obtained with both the primers were analyzed together as a single data set by calculating the average matrix from the two separate similarity matrices of the different primers to obtain a single dendogram.

\section{Results and discussion}

Initially, very small transparent shiny pinpointed colonies of about $1-1.5 \mathrm{~mm}$ diameter were randomly picked from plates streaked with the samples. Isolates appearing as Gram-positive cocci in pairs or long chains on microscopic examination were presumptively screened as $S$. thermophilus. From a total number of 500 randomly selected colonies isolated from 209 different samples of milk and milk products, 140 isolates were presumptively screened on basis of morphological examination. From the morphologically selected $140 \mathrm{~S}$. thermophilus isolates, 23 isolates were illuminated based on their ability to grow at $10{ }^{\circ} \mathrm{C}$, at 4 and $6.5 \% \mathrm{NaCl}$ concentration, in $\mathrm{pH} 9.6$, and $0.1 \%$ methylene blue. The remaining 117 isolates were found to be $S$. thermophilus on the basis of their biochemical profiles: catalase and bile esculin negative, growth in $6.5 \% \mathrm{NaCl}$, and fermented sugars, namely fructose, glucose, and mannose but did not hydrolyzed dextrose, mannitol, rhamnose, salicin, sorbitol, and xylose, which further established their identity. All these presumptive $S$. thermophilus isolates were genetically characterized by species-specific PCR using the universal primer for lacZ gene for S. thermophilus (Lick et al. 1996); all isolates gave a specific band at $968 \mathrm{bp}$ along with the positive control of NCDC 177.

In the present study, about $57 \%$ of isolates of $S$. thermophilus originated from dahi samples followed by yogurt (22.5\%) and about $12.5 \%$ from lassi, which can again be attributed to dahi, as this drinking fermented product is traditionally obtained either by churning or stirring of dahi. The present work shows the predominance of $S$. thermophilus in dahi and lassi samples.

The folate assay was performed by MA with additional tri-enzyme treatment (Tomar et al. 2009). The results of this study showed that though all isolates were found to produce folate, it was to a varied extent. The values of folate production by 117 isolates broadly fell into three ranges, and accordingly, S. thermophilus isolates were categorized into three groups, namely, high producers $\left(40-50 \mu \mathrm{g} \cdot \mathrm{L}^{-1}\right)$, which constituted $15 \%$ of the isolates, moderate producers $\left(20-30 \mu \mathrm{g} \cdot \mathrm{L}^{-1}\right)$ about $35 \%$, and low producers $\left(5-15 \mu \mathrm{g} \cdot \mathrm{L}^{-1}\right)$ up to $50 \%$. The individual folate production by the ten highest producing isolates has been depicted in Fig. 1.

Several review articles on the nutritive value of cultured dairy products, e.g., dahi, buttermilk, and yogurt, have reported that the folate content of such milk products vary widely, ranging from 4-19 $\mu \mathrm{g} 100 \mathrm{~g}^{-1}$. The results obtained from this study reveal that 


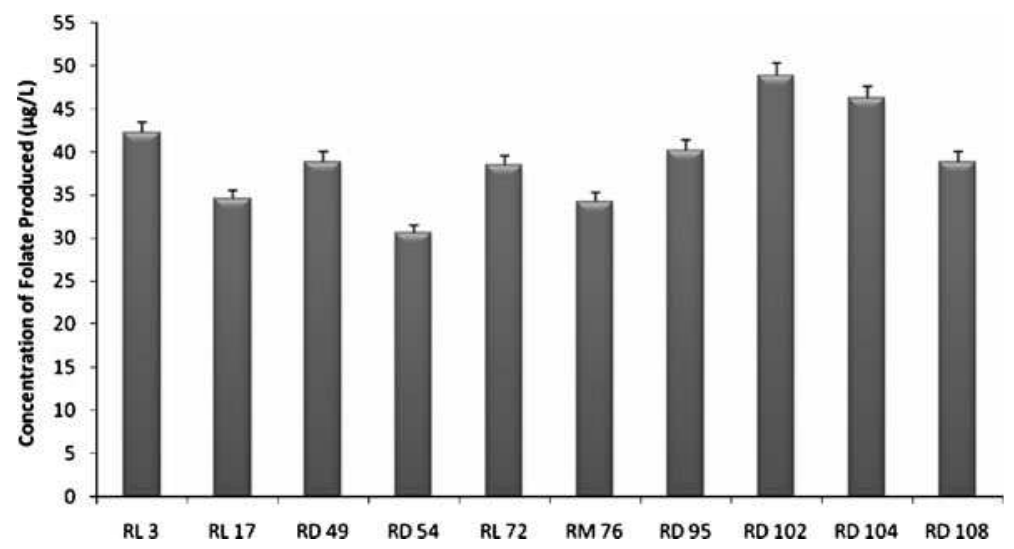

Fig. 1 Folate production by selected Streptococcus thermophilus isolates

the MA with the tri-enzyme method led to a better folate release, and thus, total folate content of samples was estimated, which are in agreement with published data (Arcot et al. 2005; Forssen et al. 2000). The performance of this method has been found to be equally satisfactory while estimating folate content of milks of different milk species in another study carried out in our laboratory (Iyer et al. 2009).

Milk is an excellent source of most B vitamins, with the notable exception of folic acid. On the basis of MA, the estimated average values of folate in goat, cow, sheep, and buffalo milks were found to be $10,44,56$, and $60 \mu \mathrm{g} \cdot \mathrm{L}^{-1}$, respectively (Iyer et al. 2009). Fermented milk products are reported to contain even higher amounts of folate. This high level is the result of the production of additional folates by bacteria (Lin and Young 2000; Sybesma et al. 2003). However, many bacteria synthesize this cofactor by themselves from simple precursors, but some auxotrophic bacteria, including many lactic acid bacteria, have a strict growth requirement for folic acid. The production and consumption of folates by the microorganisms used will be probably the most important factor determining the folate level in fermented milk products. Numerous researchers have reported different LAB, such as L. lactis, $S$. thermophilus, Leuconostoc spp., and Bifidobacterium spp., which have the ability to synthesize folate, whereas Lactobacilli species (except Lactobacillus plantarum at low levels) to consume folate. These bacteria are strain-specific prolific folate producers and produce it both extracellularly and intracellularly to variable extents (LeBlanc et al. 2007). The majority of folate produced by L. lactis, Leuconostoc spp., Propionibacteria spp., and Bifidobacteria spp. is intracellular and is not excreted into the milk and hence has a lower bioavailability (Crittenden et al. 2003; Holasova et al. 2004; Lin and Young 2000). On the other hand, S. thermophilus strains produce higher quantities of folate extracellularly during growth in milk, thereby elevating folate levels approximately fourfold (Holasova et al. 2004; Lin and Young 2000; Papastoyiannidis et al. 2006; Sybesma et al. 2003).

A striking observation is the difference in the abilities of different $S$. thermophilus strains to excrete folate. A great difference has been observed in the production ability of individual strains, thus indicating this attribute as strain specific. Using different $S$. thermophilus strains in yoghurt production, the folate contents were found to vary from 2 up to $15 \mu \mathrm{g} 100 \mathrm{~g}^{-1}$ (Smid et al. 2001) showing about more 
than sixfold increase in the folate content (Papastoyiannidis et al. 2006). The reason may be that some strains, clearly, retain all the folate intracellularly, while in other strains, almost complete excretion or leakage of the folate is observed. This, presumably, is a result of the different forms of folate that are produced by these organisms (Sybesma et al. 2003; Tomar et al. 2009). Consequently, it may be possible that some strains used in the current experiment did produce folic acid, which was not excreted to the environment (skim milk).

In the present study, all the isolates were observed to invariably produce folate, and half of the isolates were found to be reasonably good folate producers. Their folate production can possibly be further enhanced by judicious selection of cultivation conditions as the folate production by LAB has been observed to depend on the composition of the medium, e.g., carbon and nitrogen sources, growth factors, and the conditions in which the strains grow, e.g., temperature, $\mathrm{pH}$, oxygen tension, and incubation time (Lin and Young 2000; Sybesma et al. 2003; Tomar et al. 2009).

In the present study, RAPD-PCR with two randomly designed primers (M13 and AP4) was used for the characterization of the interspecific differences between the ten selected high folate producing isolates. The PCR fingerprints with primer M13 and AP4 are demonstrated in Fig. 2. The data on the relationships (similarity) between the strains of $S$. thermophilus studied are presented as (\%) equivalents. Cluster analysis of the gel patterns showed a high level of divergence within the species of $S$. thermophilus. The single two-dimensional dendogram presented in Fig. 3 derived from the combined RAPD-PCR profiles of these isolates most adequately reflected the relatedness and interrelations between the strains. The calculated value of the cophenetic correlation coefficient for the dendrogram was $0.75 \%$, indicating good reliability. The isolates were grouped into two wellseparated clusters with the type strains of $S$. thermophilus (cluster A) and $S$. thermophilus (cluster B) at a similarity level of 7\% and 13.2\%. Cluster A included two group $A_{1}$ and $A_{2}$ at a similarity level of $16.5 \%$ and $23 \%$, respectively. At a similarity level of $16.5 \%$, two S. thermophilus isolates (RL 17 and RL 72) from lassi were grouped into group $\mathrm{A}_{1}$. All isolates belonging to group $\mathrm{A}_{2}$ were further grouped into two subgroups at a similarity level of near about $29 \%$ and $33.5 \%$. This group consisted of the type strain MTCC 1938, which has a $29 \%$ similarity with two isolates RD 49 and RM 76 of its subgroup and four isolates (RL 3, RD

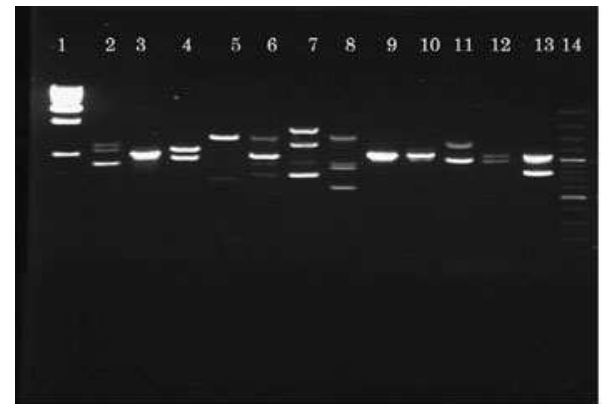

a

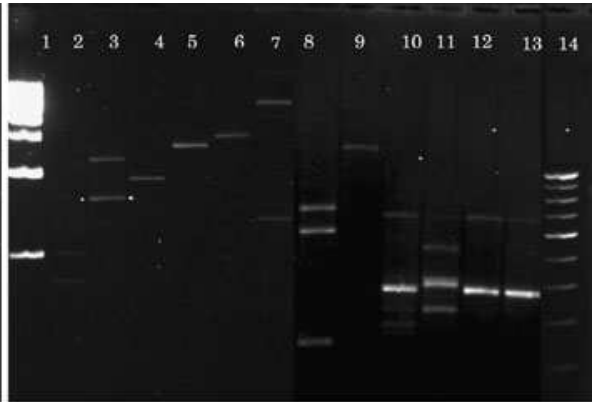

b

Fig. 2 RAPD-PCR patterns obtained with primers a M13 and b AP4. Lane 1-1000bp Molecular Weight Marker. Lanes 2 through 13-Streptococcus thermophilus NCDC177, MTCC1938, RL3, RL17, RD49, RD54, RL72, RM76, RD95, RD102, RD104, and RD108 respectively 
Fig. 3 UPGMA-based dendogram from RAPD-PCR profiles of high folate producing Streptococcus thermophilus strains and type strains obtained with M13 and AP4 primers

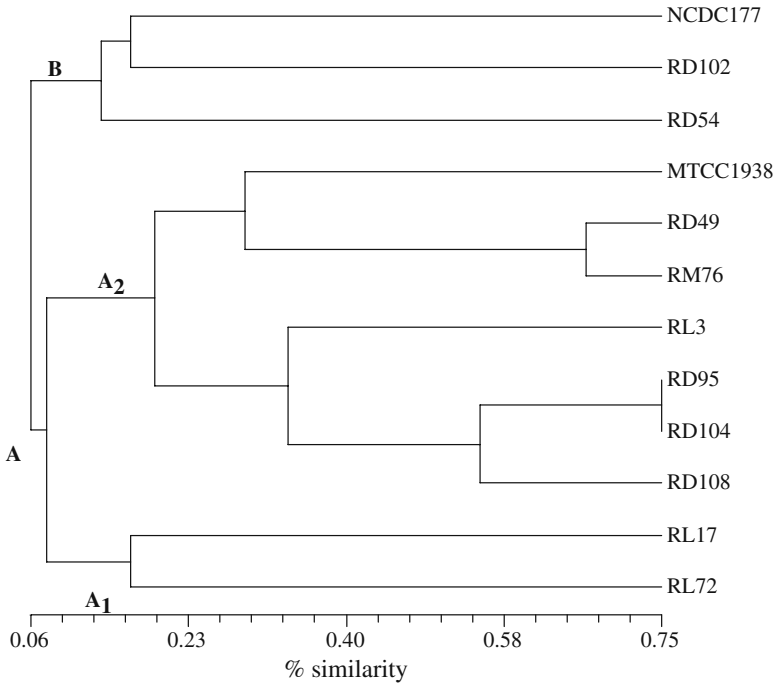

95, RD 104, and RD 108) of the other. Cluster B included a group consisting of type strain NCDC 177 and RD 102 at a similarity level of $16.5 \%$ and a single strain (RD 54) at similarity level of about 13\%. Out of all the strains, RD 95 and RD 104 were the most similar with a similarity level of approximately $87 \%$. The type strains, S. thermophilus NCDC 177 and MTCC 1938, were placed at a similarity level of $16.5 \%$ and $29 \%$, with the rest of the strains analyzed. Thus, our results showed a high degree of genetic diversity among the profiles of cluster $\mathrm{A}$ as compared to cluster B.

In the present study, RAPD-PCR with the two randomly designed primers (M13 and AP4) was used for the first time for typing of $S$. thermophilus by means of RAPD-PCR. As compared to AP4, the M13 primer showed genomic variability among the strains in a very precise manner because of the presence of very intense polymorphic bands. Hence, RAPD-PCR amplification with the M13 primer proved to be superior for distinguishing individual strains. In the present study, a significant genetic heterogeneity of the ten species and two reference type strains of $S$. thermophilus were demonstrated by the pronounced differences among the RAPD-PCR profiles obtained with the primers M13 and AP4.

Vuyst et al. (2002) studied the biodiversity of the wild LAB microflora from the Seven Greek traditional wheat sourdoughs sampled from different geographical areas of Greece by RAPD-PCR and showed one major (cluster II) comprising of 16 out of 27 strains with a correlation of $79 \%$ and two minor, clusters I (five strains) at $60 \%$ correlation and cluster III (six strains) at a 62\%. Similarly Andrighetto et al. (2002) analysed the genetic variability within $218 \mathrm{~S}$. thermophilus isolates from Italian traditional cheeses by RAPD-PCR and showed five major clusters at $60 \%$ similarity level. Later, Yousif et al. (2005) showed considerable degree of genomic diversity between 21 Enterococcus isolates from Hussuwa fermentations carried out in different surroundings by RAPD-PCR genotyping using M13 and AP4 primer. Omar et al.(2006) also evaluated the genetic diversity of seven isolates from ben saalga, a traditional fermented gruel from Burkina Faso using primer M13 and AP4, 
and found that six of the isolates were genetically different, indicating that they were in fact different strains.

Thus, a comparison of RAPD-PCR data obtained with a combination of several primers designed for either conserved or variable regions of bacterial genome makes it possible to get an idea on the interspecific diversity of $S$. thermophilus. This modified PCR program used for RAPD PCR was found to be more efficient than that described by Botina et al. (2007) and Andrighetto et al. (2001, 2002). On the basis of RAPD, no clear correlation can be deduced between RAPD clusters and folate production by isolates.

Sequencing was performed for the highest folate producer strains RD102 and RD104 using forward and reverse primers of the lacZ gene. The sequences of both the strains were correctly aligned using Bioedit Sequence Alignment Editor software, which gave a clean readable sequence of $878 \mathrm{bp}$. These 878 -bp sequence of isolates RD102 and RD104 has been submitted to Genbank with accession number FJ161697 and FJ161698, respectively. On sequence similarity search (Blast, NCBI), both the gene sequences (RD 102 and RD 104) showed 100\% homology at both nucleotide and amino acid level.

\section{Conclusion}

The predominance of $S$. thermophilus in fermented milk products has been observed in this study and suggests the extent of natural diversity of $S$. thermophilus strains among milk and fermented milk products with respect to their isolation. The ability of $S$. thermophilus to produce folate and its efficient estimation by MA using tri-enzyme extraction method has been endorsed by this study. However, this attribute of $S$. thermophilus has been found to be strain specific, and hence, selection of high producing strains is of immense importance. The bioprospecting of milk and milk products for $S$. thermophilus in the present investigation has culminated in the identification of two promising folate producing strains (RD 102 and RD 104). The folate production by selected strains can be further enhanced by identifying critical cultivation factors and optimizing this using response surface methodology. Therefore, with this functional attribute, $S$. thermophilus along with their conventional excellent technological performance can be commercially exploited as a potential cost effective functional starter to develop and formulate functional foods and nutraceuticals.

\section{References}

Andrighetto C, Knijff E, Lombardi A, Torriani S, Vancanneyt M, Kersters K, Swins J, Dellaglio F (2001) Phenotypic and genetic diversity of enterococci isolated from Italian cheeses. J Dairy Res 68:303-316 Andrighetto C, Borney F, Barmaz A, Stefanon B, Lombardi A (2002) Genetic diversity of Streptococcus thermophilus strains isolated from Italian traditional cheeses. Int Dairy J 12:141-144

Arcot J, Shrestha J (2005) Folate methods of analysis. Trends Food Sci Technol 16:253-266

Botina SG, Piksasova OV, Tsygankov YD, Sukhodolets VV (2007) Genetic diversity of the natural strains of Streptococcus thermophilus. Russ J Genet 43:485-491

Crittenden RG, Martinez NR, Playne MJ (2003) Synthesis and utilization of folate by yogurt starter cultures and probiotic bacteria. Int J Food Microbiol 80:217-222 
Delorme C (2008) Safety aspects of dairy microorganism Streptococcus thermophilus. Int J Food Microbiol 126:274-277

Forssen KM, Jagerstad MI, Wigertz K, Witthoft CM (2000) Folates and dairy products: a critical update. J Am Coll Nutr 19:100S-110S

Holasova M, Fiedlerova V, Roubal P, Pechacova M (2004) Biosynthesis of folates by lactic acid bacteria and propionibacteria in fermented milk. Czech J Food Sci 22:175-181

Hols P, Hancy F, Fontaine L, Grossiord B, Prozzi D, Leblond-Bourget N, Decaris B, Bolotin A, Delorme C, Ehrlich SD, Guedon E, Monnet V, Renault P, Kleerebezem M (2005) New insights in the molecular biology and physiology of Streptococcus thermophilus revealed by comparative genomics. FEMS Microbiol Rev 29:435-463

Iyer R, Tomar SK, Singh R, Sharma R (2009) Estimation of folate in milk by microbiological assay using trienzyme extraction method. Milchwissenschaft 64:125-127

LeBlanc JG, Giori GSD, Smid EJ, Hugenholtz J, Sesma F (2007) Folate production by lactic acid bacteria and other food-grade microorganisms. In: Mendez-Vilas A (ed) Communicating current research and educational topics and trends in applied microbiology, vol 1. Formatex, Badajoz, pp 329-339

Lick S, Keller M, Bockelmann W, Heller K (1996) Rapid identification of Streptococcus thermophilus by primer-specific PCR amplification based on its lacZ gene. Syst Appl Microbiol 19:74-77

Lin MY, Young CM (2000) Folate levels in cultures of lactic acid bacteria. Int Dairy J 10:409-414

Omar NB, Abriouel H, Lucas R, Martínez-Canãmero M, Guyot HA, Gálvez A (2006) Isolation of bacteriocinogenic Lactobacillus plantarum strains from ben saalga, a traditional fermented gruel from Burkina Faso. Int J Food Microbiol 112:44-50

Papastoyiannidis G, Polychroniadou A, Michaelidou AM, Alichandis E (2006) Fermented milks fortified with B-group vitamins: vitamin stability and effect on resulting products. Food Sci Technol Int 12:521-529

Pospiech A, Neumann BA (1995) Versatile quick-prep of genomic DNA from Gram-positive bacteria. Trends Genet 11:217-218

Smid EJ, Starrenburg MJC, Mierau I, Sybesma W, Hugenholtz J (2001) Increase of folate levels in fermented foods. Innov Food Technol 10:13-15

Sybesma W, Starrenburg M, Kleerebezem M, Mierau I, Hugenholtz J (2003) Increased production of folate by metabolic engineering of Lactococcus lactis. Appl Environ Microbiol 69:3069-3076

Tomar SK, Srivatsa N, Iyer R, Singh R (2009) Estimation of folate production by S. thermophilus using modified microbiological assay. Milchwissenschaft 84:260-263

Vuyst LD, Schrijvers V, Paramithiotis S, Hoste B, Vancanneyt M, Swings J, Kalantzopoulos G, Tsakalidou E, Messens W (2002) The biodiversity of lactic acid bacteria in Greek traditional wheat sourdoughs is reflected in both composition and metabolite formation. Appl Environ Microbiol 68:6059-6069

Wright J, Dainty J, Finglas P (2007) Folic acid metabolism in human subjects revisited: potential implications for proposed mandatory folic acid fortification in the UK. Br J Nutr 98:665-666

Yousif NMK, Dawyndt P, Abriouel H, Wijaya A, Schillinger U, Vancanneyt M, Swings J, Dirar HA, Holzapfel WH, Franz CMAP (2005) Molecular characterization, technological properties and safety aspects of enterococci from 'Hussuwa', an African fermented sorghum product. J Appl Microbiol 98:216-228 